\title{
Modeling of shear stiffness reduction from database of axial load tests on pile foundations
}

\author{
Fawad S. Niazi ${ }^{1, *}$, and Paul W. Mayne ${ }^{2}$ \\ ${ }^{1}$ Purdue University Fort Wayne, 2101 East Coliseum Boulevard, Fort Wayne, Indiana 46805-1499, USA \\ ${ }^{2}$ Georgia Institute of Technology, 790 Atlantic Drive, Atlanta, GA 30332, USA
}

\begin{abstract}
Initiating at the small-strain shear modulus $\left(G_{\max }\right)$, the mechanical nonlinear stress-strain-strength behavior of soil manifests in the form of modulus reduction, typically expressed in normalized form as $G_{\text {op }} / G_{\max }$. Here, $G_{\text {op }}$ is the operative shear modulus - a reduced stiffness value corresponding to strain levels that the soil is experiencing. Assessment of $G_{\text {op }}$ is critical to reliable predictions of load-related deformations within the soil. Among the various categories of loading, deep foundations and pilings exhibit a typical mechanism of axial load transfer to the foundation soil. For friction type piles, the stiffness reduction mostly takes place along the pile shaft-soil interface. Within the framework of an analytical solution, the back analyses from the results of load tests on pile foundations, together with the knowledge of pile geometries and soil parameters, provide an outline for evaluation of $G_{\mathrm{op}}$ at different load increments. This paper explains the methodology employed to develop stiffness reduction curves $\left(G_{\mathrm{op}} / G_{\mathrm{max}}\right)$ as a function of pseudo-strain $\left(\gamma_{\mathrm{p}}\right.$ $\left.=w_{\mathrm{t}} / d\right)$, where, $w_{\mathrm{t}}=$ settlement at the pile top, and $d=$ pile diameter. Algorithms that integrate the plasticity characteristics of the soil are also presented. The results afford an improved evaluation of the complete nonlinear load-settlement $\left(Q-w_{\mathrm{t}}\right)$ response for pile foundations under axial loads.
\end{abstract}

\section{Introduction}

The relevance of the small-strain stiffness of soils, as represented by $G_{\max }$, has been a common thread in many research studies over the past three decades $[1,2]$. Findings presented in the previous six symposia on the theme: Deformation Characteristics of Geomaterials have contributed to advancing the state of the art and state of practice on the importance of $G_{\max }$ as the starting point for stress-strain-strength response in natural soils, as well as engineered and stabilized geomaterials. Families of modulus reduction curves have also been developed to represent the deformation response of geomaterials for static, cyclic or dynamic load applications $[3,4,5,6,7,8$, 9]. These include formulations of normalized secant shear modulus $\left(G / G_{\max }\right)$ as a function of shear strain $(\gamma)$, normalized shear strain $\left(\gamma / \gamma_{\text {ref }}\right)$, or normalized shear stress $\left(\tau / \tau_{\max }\right)$, where $\gamma_{\text {ref }}=$ reference strain, $\tau=$ shear stress, and $\tau_{\max }=$ shear strength of the soil.

Among the various categories of loading, deep foundations in the form of piles exhibit a typical mechanism of static axial load transfer to the foundation geomaterials. In particular, if the pile is floating (aka friction) type, the stiffness reduction mostly takes place along the pile shaft-geomaterial interface. Having an appropriate modulus reduction scheme that accounts for important geomaterial parameters, pile geometry, and equally relevant pile typology (as related to the method of installation that inherently accounts for pile interaction with the surrounding geomaterials along the shaft interface) offers convenience in improved assessment of this load-settlement $(Q-w)$ response. Such a model can be developed via a semi-empirical approach of integrating field data with a rational analytical solution. In this regard, a reliable database of full-scale and prototype load tests on pile foundations serves the required needs.

This paper summarizes a methodology employed by the authors in generating a new family of shear modulus reduction schemes specifically meant for use in pile foundations along with an overview of the database employed for this purpose. A new graphical model with its associated algorithms are also presented together with a flowchart for its implementation in predicting the nonlinear axial $Q-w$ response of single pile foundations.

\section{Pile database}

An extensive database of 312 well-documented case records of axial pile load tests from 62 worldwide sites was utilized in this study. The pile database was sorted in two broad categories: (1) non-displacement types (i.e., drilled shafts, bored piles, continuous flight auger), and (2) driven or jacked, and displacement types (i.e., closeand open-ended circular and H-section steel, square and circular section prestressed concrete, spun cast concrete, and timber). Information on range of pile lengths and diameters are summarized in Table 1, while an overview of the diverse range and types of geomaterials are presented in Table 2.

\footnotetext{
"Corresponding author: niazif@pfw.edu
} 
Table 1. Characteristics of piles in the database.

\begin{tabular}{|c|c|c|}
\hline & $\begin{array}{c}\text { Non-displacement } \\
\text { type piles } \\
\text { (bored and augered) }\end{array}$ & $\begin{array}{c}\text { Displacement type } \\
\text { piles } \\
\text { (driven and jacked) }\end{array}$ \\
\hline $\begin{array}{c}\text { Quantity of } \\
\text { test piles }\end{array}$ & 66 & 246 \\
\hline $\begin{array}{c}\text { Range of } \\
\text { pile length }\end{array}$ & 4.5 to $52.4 \mathrm{~m}$ & 1.83 to $100 \mathrm{~m}$ \\
\hline $\begin{array}{c}\text { Range of } \\
\text { pile diameter }\end{array}$ & 0.168 to $2.5 \mathrm{~m}$ & 0.034 to $1.824 \mathrm{~m}$ \\
\hline
\end{tabular}

Table 2. General information of geomaterials in the database.

\begin{tabular}{|c|c|}
\hline $\begin{array}{c}\text { Nature of } \\
\text { information }\end{array}$ & Details of related information \\
\hline $\begin{array}{c}\text { Types of } \\
\text { geomaterials }\end{array}$ & $\begin{array}{c}\text { Soft sensitive to stiff and fissured clays; } \\
\text { loose to very dense sands; gravelly sands, } \\
\text { and mixed soils of different combinations }\end{array}$ \\
\hline $\begin{array}{c}\text { Consolidation } \\
\text { histories }\end{array}$ & $\begin{array}{c}\text { Normally consolidated to heavily } \\
\text { overconsolidated (OCR from 1 to 40) }\end{array}$ \\
\hline $\begin{array}{c}\text { Plasticity } \\
\text { characteristics }\end{array}$ & $\begin{array}{c}\text { Non-plastic (i.e., sands) to highly plastic } \\
\text { clays (PI ranging from 5 to 105) }\end{array}$ \\
\hline
\end{tabular}

Comprehensive information of the case records is available in [10].

The $G_{\max }$ profiles at these sites were established from the measurements of shear wave velocity $\left(V_{\mathrm{s}}\right)$ obtained via seismic cone penetration tests, seismic dilatometer tests, spectral analysis of surface waves, or standard downhole tests, and in only few cases via well established correlations. The following well-known relationship was used for $G_{\max }$ determination:

$$
G_{\max }=\rho_{t} V_{s}^{2}
$$

where $\rho_{\mathrm{t}}=$ total soil mass density. The $G_{\max }$ profiles and the related modulus variation factor $\left(\rho_{\mathrm{E}}\right)$ at these sites mostly indicated either relatively uniform conditions or general Gibson soil types.

\section{Synopsis of the analytical elastic solution}

For the purpose of this study, the Randolph analytical elastic closed form solution [12] was employed which represents load-settlement relationship for a single pile foundation:

$$
w_{\mathrm{t}}=\frac{Q_{\mathrm{t}}\left[1+\frac{4 \eta \tanh (\mu L) L}{\pi \lambda\left(1-v_{\mathrm{S}}\right) \xi(\mu L) r_{\mathrm{o}}}\right]}{G_{\mathrm{L}} r_{\mathrm{O}}\left[\frac{4 \eta}{\left(1-v_{\mathrm{S}}\right) \xi}+\frac{2 \pi \rho_{\mathrm{E}} \tanh (\mu L) L}{\zeta(\mu L) r_{\mathrm{O}}}\right]}
$$

where $w_{\mathrm{t}}=$ settlement at the pile top; $Q_{\mathrm{t}}=$ applied load at the pile top; $G_{\mathrm{L}}=$ operative soil shear modulus at the reference depth of pile base $(z=L) ; r_{\mathrm{o}}=d_{\mathrm{s}} / 2=$ radius of pile shaft; $d_{\mathrm{s}}=$ pile shaft diameter; $\eta=r_{\mathrm{b}} / r_{\mathrm{o}}=$ eta factor for under reamed piles; $r_{\mathrm{b}}=d_{\mathrm{b}} / 2=$ pile base radius for under reamed piles; $d_{\mathrm{b}}=$ pile base diameter; $v_{\mathrm{s}}=$ Poisson's ratio of soil; $\xi=G_{\mathrm{L}} / G_{\mathrm{b}}=$ zeta factor for end bearing piles resting on stiffer stratum (where $G_{\mathrm{b}}>G_{\mathrm{L}}$ ); $G_{\mathrm{b}}=$ soil shear modulus below pile base; $\rho_{\mathrm{E}}=$ modulus variation factor $=$ $G_{\mathrm{M}} / G_{\mathrm{L}} ; G_{\mathrm{M}}=$ operative soil shear modulus at mid of pile embedment depth $=\left[G_{\mathrm{o}}+G_{\mathrm{L}}\right] / 2 ; G_{\mathrm{o}}=$ operative soil shear modulus at the ground surface (at pile top, where $z=0$ ); $L=$ embedded length of the pile; $\zeta=$ measure of average radius of influence in the surrounding soil mass affected by shearing stresses around the pile $=\ln \left(r_{\mathrm{m}} / r_{\mathrm{o}}\right) ; r_{\mathrm{m}}=$ maximum influence radius along embedded length of the pile $=L\left\{0.25+\xi\left[2.5 \rho_{\mathrm{E}}\left(1-v_{\mathrm{s}}\right)-0.25\right]\right\} ; \mu L=$ the measure of pile compressibility $\left.=[2 /(\zeta \lambda)]^{0.5}\left(L / r_{0}\right)\right\}$, and $\lambda=$ factor that accounts for pile-to-soil stiffness ratio $=$ $E_{\mathrm{p}} / G_{\mathrm{L}}$, where $E_{\mathrm{p}}=$ pile modulus. The use of the term "operative" is meant to imply the secant values of stiffness corresponding to incremental loads and the resulting strains.

The solution is modeled for a pile embedded in a linear elastic two-layered soil with the layer boundary at the pile base elevation, wherein, assumes elastic stiffness properties for the soil layers. It accounts for piles in homogeneous soils (having constant $G_{\max }$ with depth) as well as Gibson-type soil models (having a linearlyincreasing $G_{\max }$ profile with depth). It covers floating-type piles $\left(G_{\mathrm{b}}=G_{\mathrm{L}}\right)$ and end-bearing type piles where the base rests on a stiffer stratum $\left(G_{\mathrm{b}}>G_{\mathrm{L}}\right)$.

\section{Modelling methodology for stiffness degradation from pile database}

The operative shear stiffness values were back-analysed from the data of load tests following the approach adopted by [11]. Accordingly, eq. (2) was rearranged to the following shape:

$$
G_{L}=\frac{Q_{t}\left[1+\frac{4 \eta \tanh (\mu L) L}{\pi \lambda\left(1-v_{S}\right) \xi(\mu L) r_{o}}\right]}{w_{t} r_{o}\left[\frac{4 \eta}{\left(1-v_{S}\right) \xi}+\frac{2 \pi \rho_{E} \tanh (\mu L) L}{\zeta(\mu L) r_{o}}\right]}
$$

The sets of applied loads $\left(Q_{\mathrm{t}}\right)$ and their corresponding measured settlements $\left(w_{\mathrm{t}}\right)$ from each load test were used in the above equation. The remaining input parameters and properties, including pile geometry, the pile-soil stiffness ratios $\left(\lambda=E_{\mathrm{p}} / G_{\mathrm{L}}\right)$ and the measure of pile compressibility $(\mu L)$, were adopted from the documented record of their respective data sources. Unless otherwise known from the original data source, the following assumptions were made for the soil Poisson's ratio $\left(v_{\mathrm{s}}\right)$ values: drained conditions for predominantly sandy soils $\left(v_{\mathrm{s}}=0.2\right)$, while undrained conditions for predominantly clayey soil layers $\left(v_{\mathrm{s}}=0.5\right)$.

Built within the framework of this back-analysis are the following two assumptions that are reasonably acceptable from an engineering perspective: (1) the stiffness is linearly dependent on the depth, although some field situations may portray a different trend, and (2) the back-analysed field stiffness can be obtained keeping $\rho_{\text {E }}$ constant, i.e., under the influence of increasing loads, the corresponding $G_{\text {op }}$ along the shaft and at the base reduces at the same rate, although the shaft resistance is expected to mobilize prior to the end bearing. It should also be noted that $G_{\mathrm{L}}$ is inherently built within the 
parameters on the right sides of eq. (3). It requires a trial and error approach or a computer program capable of automatically running the required number of iterations to match the values of $G_{\mathrm{L}}$ on both sides of the equation.

The operative shear modulus $\left(G_{\mathrm{op}}\right)$ values obtained in the manner summarized above were normalized as $G_{\mathrm{op}} / G_{\max }$ and specified as function of the corresponding percent normalized settlement $\left[w_{t} / d(\%)\right]$. In this study, it was not possible from the available data to directly relate and express $G_{\mathrm{op}} / G_{\max }$ values to the typical strains. Therefore, an alternative definition of pseudo-strain (i.e. $\gamma_{p}=w_{t} / d$ ) was adopted.

Presented in Figure 1 are the combined stiffness reduction trends from 312 pile load tests obtained through the back-analysis methodology explained above. As shown, the pseudo-strain $\left(\gamma_{\mathrm{p}}\right)$ axis has also been normalized with respect to a reference pseudo-strain $\left(\gamma_{\mathrm{p} \text {-ref }}\right.$ $=0.01)$. This conservative limit of $\gamma_{p-r e f}$ was adopted to bring a certain degree of compatibility with the definitions of reference strain $\left(\gamma_{\text {ref }}\right)$ typically found in the literature.

\section{Model fitting and design charts}

In order to offer convenience in the use of these trends and to develop an implementable solution, it was considered important to study the factors contributing to the general tendency as well as the scatter found in the results. One clear observation that can be made from the optics of the finding shown in Figure 1 is the overall lower rate of stiffness degradation in the case of driven and jacked piles vs. bored and augered piles. A simple explanation to that can be given based on the effect of pile installation (i.e., partial- to full-displacement vs. non-displacement) and the resulting lateral stresses that develop at the interface between the pile and the surrounding geomaterials along the shaft. This observation signifies a need for separate analyses for the two broad categories of pile foundations.

In addition to the above general observation, the evident scatter within each category points to the influence of distinct characteristics of the soil deposits within the database. From the documented records of these sites, the most valuable information relevant to this

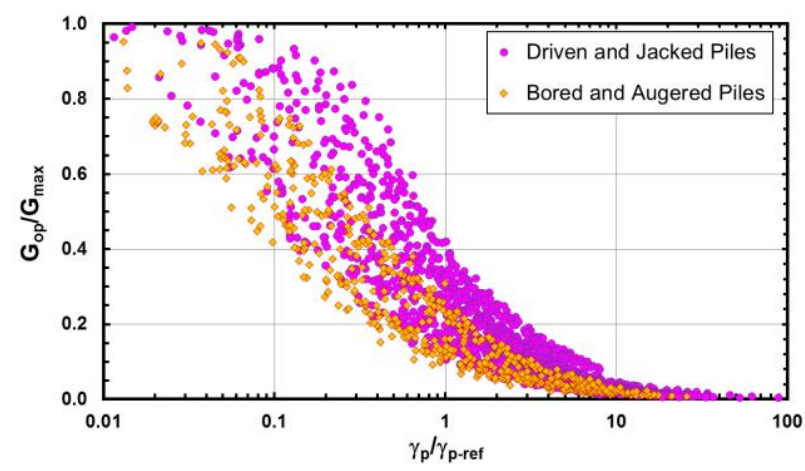

Fig. 1. General trends of stiffness reduction derived from the back-analysis of load tests with grouping based on piletypology and installation methods.

study was the plasticity characteristics, evident from the well-established PI-based trends of $G / G_{\max }$ vs. $\gamma$ (e.g., [7,
8, 9]). Accordingly, the non-plastic soils (essentially sands) were assigned a PI of zero, while cases involving fine-grained soils without plasticity information were not considered for further analysis.

To explore a linear relationship for this nonlinear trend, the response variable $\left(G_{\mathrm{op}} / G_{\max }\right)$ was transformed to $\left(G_{\max } / G_{\text {op }}-1\right)$ and common logarithm was taken of the predictor and response variables. The slope and intercept values via linear regression of the overall general trend for the two pile categories are shown in Figure 2, backtransformation of which to the non-linear format lead to the following categorized general expressions:

Driven \& jacked piles:

$$
\frac{G_{o p}}{G_{\max }}=\frac{1}{\left[1+3.295\left(\frac{\gamma_{p}}{\gamma_{p-r e f}}\right)^{1.034}\right]}
$$

Bored \& augered piles:

$$
\frac{G_{\mathrm{op}}}{G_{\max }}=\frac{1}{\left[1+5.342\left(\frac{\gamma_{\mathrm{p}}}{\gamma_{\mathrm{p}-\mathrm{ref}}}\right)^{0.912}\right]}
$$

As evident from Figure 2, the data within each pile category was additionally sorted in attempt to quantify the influence of soil plasticity. Separate slopes and intercepts were obtained for different PI values, reverse transformations of which indicated a need of introducing adjustment to eqs. (4) and (5) in the form of coefficient $(\alpha)$ and exponent $(\beta)$ to account for PI effects. Figure 3 presents graphs where the back-calculated $\alpha$ and $\beta$ values have been plotted against their respective PI data, and the respective best-fit curves are also shown.

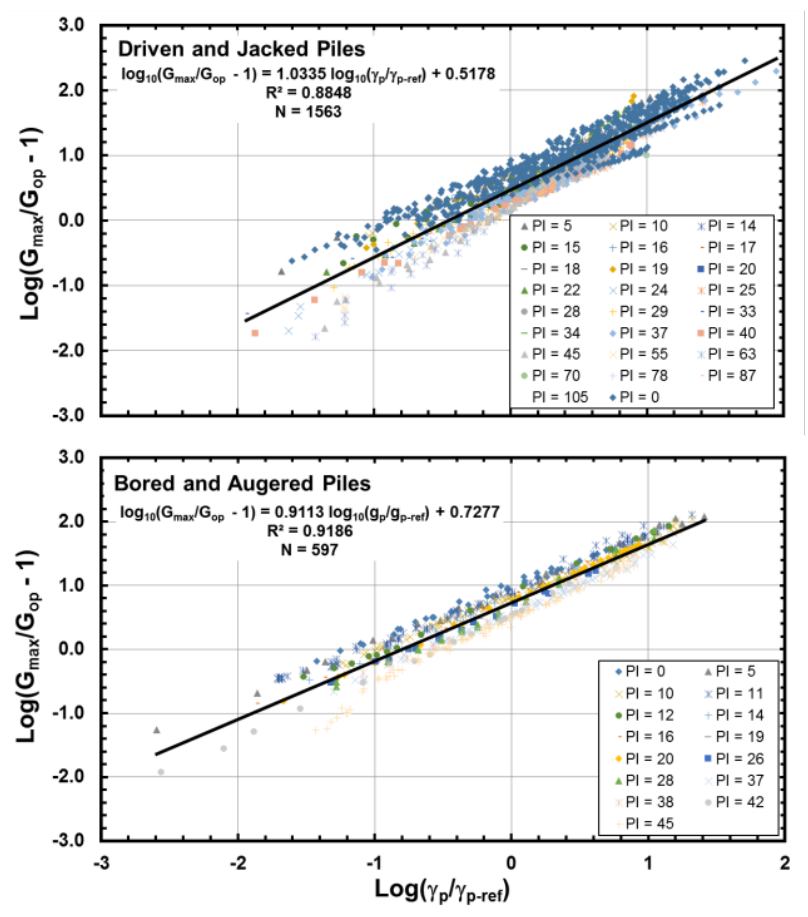

Fig. 2. Modified hyperbolic fitting of transformed predictor and response variables: $G_{\mathrm{op}} / G_{\max }$ vs. $\gamma_{\mathrm{p}} / \gamma_{\mathrm{p} \text {-ref. }}$. 

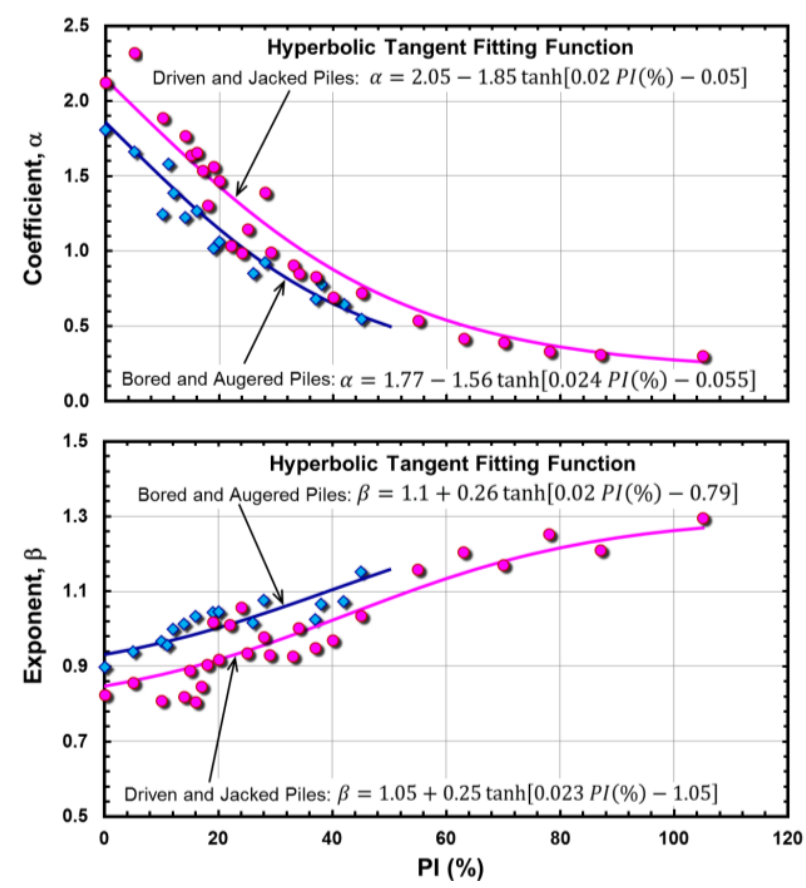

Fig. 3. Correlations for coefficient $\alpha$ and exponent $\beta$ with percent PI.

Accordingly, the modified stiffness reduction expression for driven and jacked piles takes the following shape:

$$
\left[\frac{G_{\mathrm{op}}}{G_{\mathrm{max}}}\right]_{\text {dr.\&j.p. }}=\frac{1}{\left[1+3.295 \alpha\left(\frac{\gamma_{\mathrm{p}}}{\gamma_{\mathrm{p}-\mathrm{ref}}}\right)^{1.034 \beta}\right]}
$$

where:

$$
\begin{aligned}
& \alpha_{\text {dr.\&j.p. }}=2.05-1.85 \tanh [0.02 P I(\%)-0.05] \\
& \beta_{\text {dr.\&j.p. }}=1.05+0.25 \tanh [0.023 P I(\%)-1.05]
\end{aligned}
$$

Similarly, the corresponding adjustments for bored and augered piles result in the following set of relationships:

$$
\left[\frac{G_{\mathrm{op}}}{G_{\mathrm{max}}}\right]_{\text {b.\&a.p. }}=\frac{1}{\left[1+5.342 \alpha\left(\frac{\gamma_{\mathrm{p}}}{\gamma_{\mathrm{p}-\mathrm{ref}}}\right)^{0.912 \beta}\right]}
$$

where:

$$
\begin{aligned}
& \alpha_{\text {b.\&.a.p. }}=1.8-1.56 \tanh [0.024 P I(\%)-0.05] \\
& \beta_{\text {b.\&a.p. }}=1.1+0.26 \tanh [0.02 \operatorname{PI}(\%)-0.79]
\end{aligned}
$$

The following important facts must be considered regarding the relationships presented in Figure 3 above:

- The PI values used in this analysis are the averages from the applicable layer at respective sites.

- The curves shown were forced to fit the data via a hyperbolic tangent function since simple linear regression was not considered appropriate to represent the overall trends.

- The data were generally of limited numbers in the high plasticity range, although the general trends are suitably explained via the curve fitting functions.

- The case records of bored and augered piles represent a maximum PI of $45 \%$. Since the curves appear to follow the same over trends as that of the driven and jacked piles, it is assumed that the trend continues beyond the know range of the data. The $\alpha$ and $\beta$ expressions for bored piles allow extension of the curves outside of the given range.

- It is possible that the trends may be further refined by adding newer high quality data.

- Although the sand sites were assigned PI value of zero, a similar separate analysis as above may be possible by incorporating relevant information such as density index or relative density etc. In the current sources, the data were sparse in this regard, and therefore the aforementioned simplification was adopted.

The solution described in the foregoing is presented in a concise graphical form shown in Figure 4. The predictor variable is simplified to percent pseudo-strain $\left[\gamma_{p}(\%)\right]$ from its original normalized format: $\gamma_{p} / \gamma_{p \text {-ref. Indeed, the }}$ numerical value of the selected reference pseudo-strain $\left(\gamma_{p-\text { ref }}=0.01\right)$ once expressed as percent [i.e., $\gamma_{p \text {-ref }}(\%)$ ] reduces to unity. The most important observation from the new design charts is their evident compatibility with the previously established plasticity based stiffness reduction trends [7, 8, 9]. This is besides the fact that a direct comparison cannot be performed since those previous relationships employed the classical definition of strains for the predictor variable.

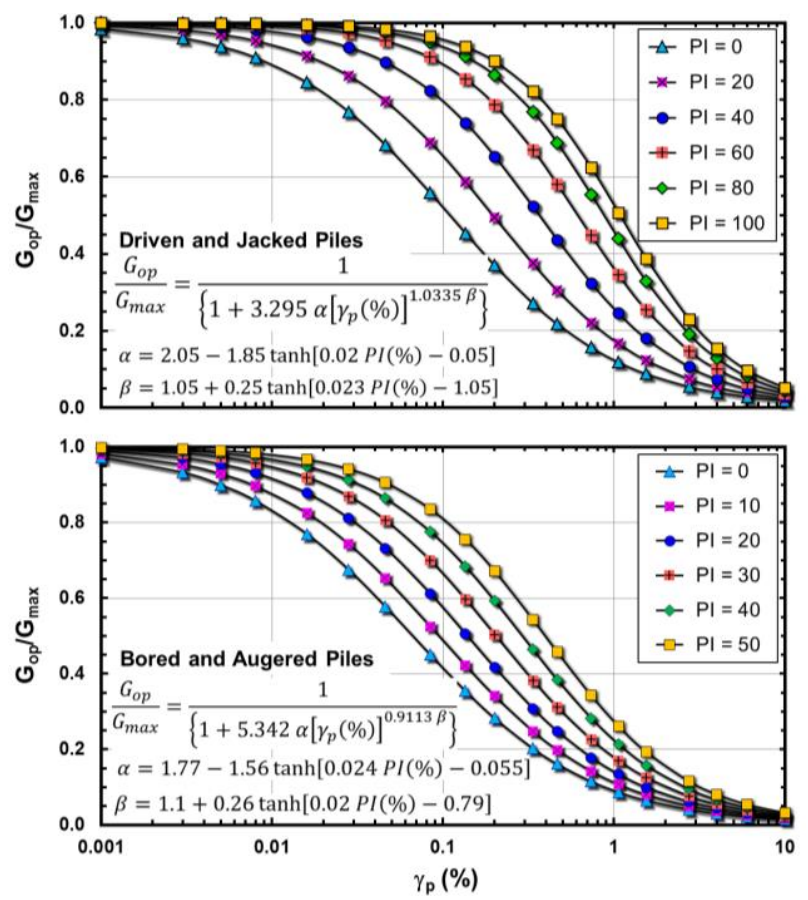

Fig. 4. Design charts for estimating operative (secant) shear modulus for settlement calculations concerning axial pile foundations. 


\section{Flow chart and solution algorithms}

The new set of design charts can be used to predict axial loads $\left(Q_{\mathrm{t}}\right)$ for selected input of settlement $\left(w_{\mathrm{t}}\right)$ values. This can be done via a hybrid approach of utilizing analytical elastic solution of eq. (2) together with the chart solution for estimating modulus reduction presented herein. The overall methodology is summarized in the flow chart shown in Figure 5.

From the details of this methodology, the solution seems to be quite complicated. Indeed, a convenient spreadsheet implementation can be developed for this entire procedure with a minimal number of geotechnical input parameters to estimate the complete $Q-w$ response of piles under axial compression type of loadings.

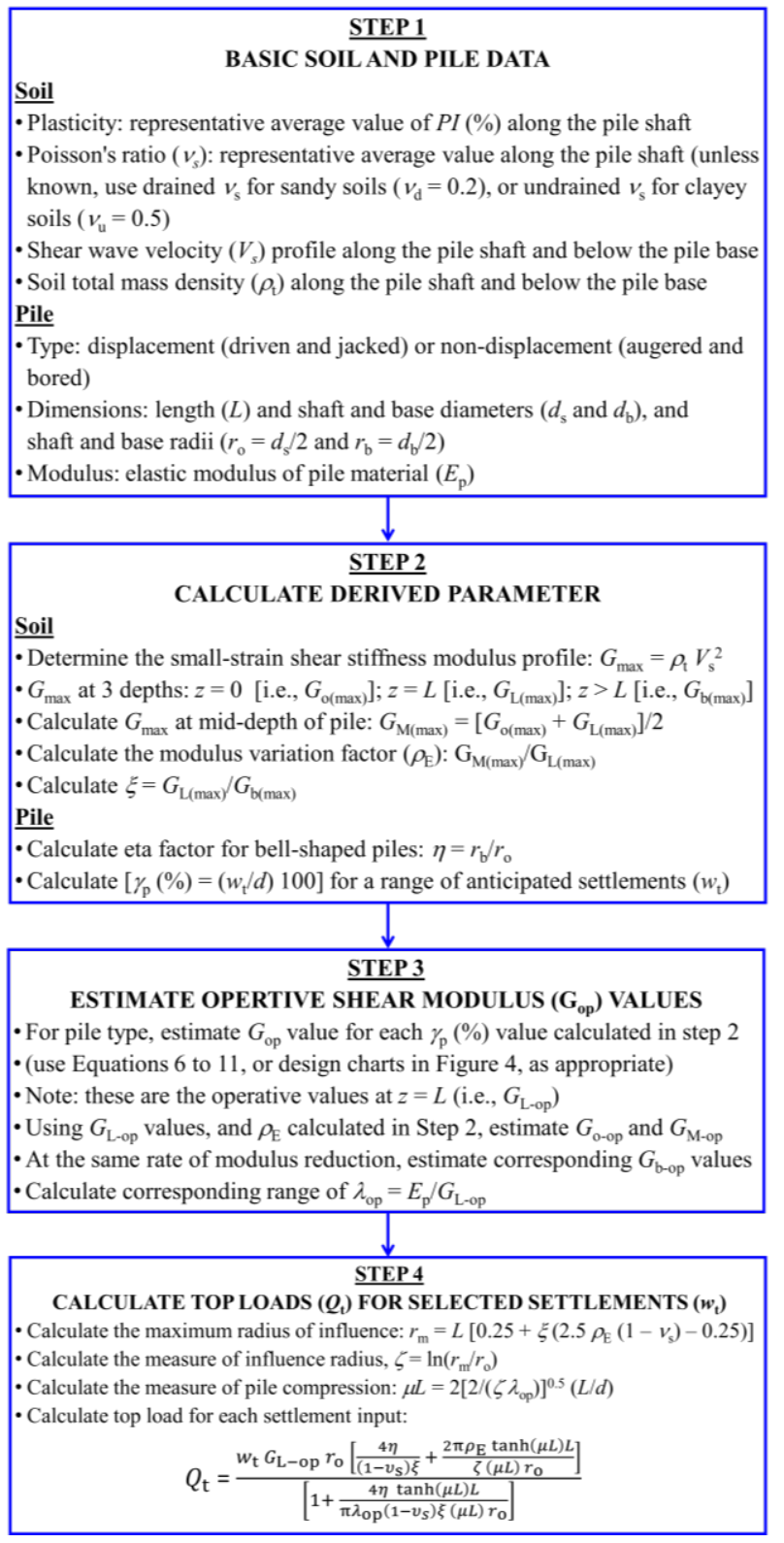

Fig. 5. Flowchart showing detailed steps for estimating pairs of settlements and corresponding loads from the $G_{\mathrm{op}} / G_{\max }$ vs. percent $\gamma_{p}$ type design charts.

\section{Summary}

A set of shear stiffness reduction charts were developed from the back-analysis of a dataset of 312 pile load tests. Herein, two simplifying assumptions were made for the back-analysis: (1) linearity of stiffness with depth (at times, this may contradict with some field situations), and (2) the rate of modulus reduction is constant with depth (this could be in disparity to the reality, in which case, the shaft resistance generally tends to mobilize prior to that of end bearing). The hyperbolic tangent expressions and the chart solutions developed herein account for the plasticity characteristics of the soil deposit. It is likely possible to further refine the methodology as well as the solution by including latest axial pile data from well-documented test sites. Specifically, for sites that present either nonuniform or non-linear stiffness variation trends with depth, these solution algorithms will require further improvement. Likewise, to account for variation in the modulus reduction with depth (as related to the decrease in the mobilized resistance in deeper segments of embedded pile), the solution should be modelled for a stack of pile segments installed in a multi-layered soil profile, where stiffness reduction takes its respective trend within each layer. Such a solution is presently being refined by the authors.

The primary focus of this article is presentation of the methodology adopted by the authors to formulate a new family of shear modulus reduction schemes specifically meant for use in the axial pile foundations. Beyond that, a step-by-step scheme of implementing the proposed model is also offered. This article extends an opportunity to other researchers having access to alternative and latest data to follow the proposed methodology for updating these modulus reduction curves or alternatively formulating site-specific curves. While the authors have successfully implemented the proposed methodology on few newer cases of pile foundations, further extension and compilation is underway to be offered as part of a comprehensive analysis and findings in due course of time.

\section{References}

1. S.E. Burns, P.W. Mayne, J.C. Santamarina, Editors $4^{\text {th }}$ Int. Symp. on Deformation Characteristics of Geomaterials, IS Atlanta (2008)

2. V.A. Rinaldi, M.E. Zeballos, J.J. Clariá., Editors. $6^{\text {th }}$ Int. Symp. on Deformation Characteristics of Geomaterials, IS-Buenos Aires (2015)

3. M.B. Darendeli, Development of a new family of normalized modulus reduction and material damping curves. Ph.D. Thesis, University of Texas at Austin (2001)

4. M. Fahey, J.P. Carter, Can. Geotech. J., 30, 2, 348362 (1993)

5. B.O. Hardin, V.P. Drnevich, ASCE J. Soil Mech. Found. Div., 98, SM7, 667-691 (1972)

6. I. Ishibashi, X. Zhang, Soils \& Found., 33, 1, 182-191 (1993) 
7. P.J. Vardanega, M.D. Bolton, "Practical methods to estimate the non-linear shear stiffness of fine grained soils." Int. Symp. Deform. Charac. Geomat., Seoul, 372-379 (2011)

8. P.J. Vardanega, M.D. Bolton, J. Geotech. Geoenviron. Engrg., 139, 9, 1575-1589 (2013)

9. M. Vucetic, R. Dobry, ASCE J. Geotech. Engrg. 117, 1, 89-107 (1991)

10. F.S. Niazi, "Static axial pile foundation response using seismic piezocone data." PhD Thesis, School of Civ. \& Environ. Engrg., Georgia Institute of Technology, Atlanta, GA (2014)

11. R. Berardi, R. Bovolenta, Inst. Civ. Engrg., Geotech. Engrg., 158, GE1, 35-44 (2005)

12. M.F. Randolph, PIGLET: Analysis and design of pile groups. Manual Version 5.1, Centre for Offshore Foundation Systems, School of Civil and Resource Engineering, The University of Western Australia, Crawley, Western Australia: 35p (2007) 